Cite this: J. Mater. Chem. A, 2013, 1, 12627

Received 1st May 2013

Accepted 21st August 2013

DOI: $10.1039 / c 3 t a 11712 j$

www.rsc.org/MaterialsA

\title{
Plasmon-enhanced photocurrent in quasi-solid-state dye-sensitized solar cells by the inclusion of gold/silica core-shell nanoparticles in a $\mathrm{TiO}_{2}$ photoanode $\uparrow$
}

\begin{abstract}
Sanghyuk Wooh,,$^{\mathrm{ab}}$ Yong-Gun Lee,,$^{\mathrm{c}}$ Muhammad Nawaz Tahir, ${ }^{\mathrm{d}}$ Donghoon Song, ${ }^{\mathrm{c}}$ Michael Meister, ${ }^{e}$ Frédéric Laquai, ${ }^{e}$ Wolfgang Tremel, ${ }^{d}$ Juan Bisquert, ${ }^{f}$ Yong Soo Kang ${ }^{\star c}$ and Kookheon Char ${ }^{\star a b}$

Direct evidence of the effects of the localized surface plasmon resonance (LSPR) of gold nanoparticles (Au NPs) in $\mathrm{TiO}_{2}$ photoanodes on the performance enhancement in quasi-solid-state dye-sensitized solar cells (DSCs) is reported by comparing gold/silica core-shell nanoparticles (Au@ $\mathrm{SiO}_{2} \mathrm{NPs}$ ) and hollow silica nanoparticles with the same shell size of the core-shell nanoparticles. The Au nanoparticles were shelled by a thin $\mathrm{SiO}_{2}$ layer to produce the core-shell structure, and the $\mathrm{SiO}_{2}$ hollow spheres were made by dissolving the Au cores of the gold/silica core-shell nanoparticles. Therefore, the size and morphology of the $\mathrm{SiO}_{2}$ hollow spheres were the same as the Au@SiO 2 NPs. The energy conversion efficiency was improved nearly 36\% upon incorporating the Au nanoparticles, mostly due to the increase in $J_{\mathrm{sc}}$, while $V_{\mathrm{oc}}$ and FF were unchanged. The improvement was mostly contributed by the LSPR of the Au@SiO 2 NPs, whereas the other parameters, such as the electron lifetime and electron diffusion coefficient, were nearly unchanged. Therefore, LSPR is an effective tool in improving the photocurrent and consequently the performance of DSCs.
\end{abstract}

\section{Introduction}

Dye-sensitized solar cells (DSCs) have currently received much attention due to several advantages, such as the low fabrication cost and high power conversion efficiency greater than $12 \%$ under 1 sun illumination condition..$^{1-4}$ The most widely studied DSC is comprised of an electrolyte sandwiched between two electrodes coated on a transparent conducting glass, such as

${ }^{a}$ Intelligent Hybrids Research Center, Seoul National University, Seoul, 151-744, Korea.E-mail: khchar@plaza.snu.ac.kr; Tel: +82 28801877

${ }^{b}$ The WCU program for Chemical Convergence for Energy and Environment, School of Chemical and Biological Engineering, Seoul National University, Seoul, 151-744, Korea

${ }^{'}$ The WCU Department of Energy Engineering and Center for Next Generation DyeSensitized Solar Cells, Hanyang University, Seoul 133-791, Korea. E-mail: kangys@ hanyang.ac.kr; Tel: +82222202336

${ }^{d}$ Institute of Inorganic Chemistry and Analytical Chemistry, Johannes GutenbergUniversity, Duesbergweg 10-14, D-55099 Mainz, Germany

${ }^{e}$ Max Planck Research Group for Organic Optoelectronics, Max-Planck-Institute for Polymer Research, Mainz, Germany

${ }^{f}$ Photovoltaics and Optoelectronic Devices Group, Departament de Física, Universitat Jaume I, 12071 Castelló, Spain

$\uparrow$ Electronic supplementary information (ESI) available: Device characterization with incident-modulated photovoltage spectroscopy (IMVS) and incident-modulated photocurrent spectroscopy (IMPS). See DOI: 10.1039/c3ta11712j

\$ These authors contributed equally to this work. fluorine-doped tin oxide (FTO) glass; a photoanode and counter electrode. The photoanode consists of a mesoporous semiconductor such as a $\mathrm{TiO}_{2}$ layer with sensitizers, whereas a typical counter electrode is made of a reduction catalyst such as platinum coated onto FTO. Upon light illumination, dye sensitizers adsorbed to the surface of the mesoporous $\mathrm{TiO}_{2}$ layer generate electrons, which are subsequently injected into the $\mathrm{TiO}_{2}$ layer for electricity production. Therefore, light absorption by sensitizers on the photoanodes plays a major role in determining the overall energy conversion efficiency of DSCs. A large body of research has been conducted to enhance the light harvesting efficiency in $\mathrm{TiO}_{2}$ photoanodes. In this context, the development of more efficient dye sensitizers, including organic dyes with a higher extinction coefficient $t^{5,6}$ and energy-relay dyes, ${ }^{7}$ and their effective utilization methods, such as cocktail dye $^{8,9}$ and selective dye adsorption ${ }^{\mathbf{1 0 , 1 1}}$ concepts, have prevailed. In addition, the introduction of a scattering layer and inverse opal nanostructures are also common. ${ }^{\mathbf{1 2 - 1 4}}$

The localized surface plasmon resonance (LSPR) phenomena of metal nanoparticles has also been investigated to enhance light harvesting efficiency. ${ }^{15-17}$ The LSPR, which refers to the resonance between the electromagnetic field and free-electron oscillation, amplifies the electromagnetic field near the metal nanoparticles, resulting in plasmon enhanced light absorption of dye sensitizers in DSCs. ${ }^{\mathbf{1 8 - 2 3}}$ The Hupp group first reported plasmon enhanced light harvesting in DSCs using silver 
nanoparticles on flat $\mathrm{TiO}_{2}$ film, demonstrating considerable potential to increase the photocurrent. ${ }^{24,25}$ The photocurrent and power conversion efficiency of the DSC increased nearly 6-7-fold upon incorporating silver nanoparticles into a dye monolayer on the flat $\mathrm{TiO}_{2}$ film $\left(J_{\mathrm{sc}}\right.$ from 14.6 to $85.7 \mu \mathrm{A} \mathrm{cm} \mathrm{cm}^{-2}$, from 0.007 to $0.045 \%$ ). Recently, enhanced charge carrier generation in solidstate DSCs was demonstrated by the LSPR effects of Au NPs coated on a mesoporous $\mathrm{TiO}_{2}$ photoanode ${ }^{26}$ and a hexagonal array of Ag nanodome-structured counter electrode. ${ }^{27}$

Direct effects of LSPR by metallic nanoparticles on the performance of DSCs may not be readily evaluated in common $\mathrm{I}^{-} / \mathrm{I}_{3}{ }^{-}$redox couples which dissolve metallic nanoparticles, such as gold, by the following reaction: ${ }^{28}$

$$
2 \mathrm{Au}+\mathrm{I}_{3}^{-}+\mathrm{I}^{-} \leftrightarrows 2\left[\mathrm{AuI}_{2}\right]^{-}
$$

One way to avoid the dissolution problem of metallic nanoparticles is to create a shell with an inert material, such as $\mathrm{SiO}_{2}$. In this study, $\mathrm{Au} @ \mathrm{SiO}_{2}$ NPs were synthesized in a solution process and mixed with a $\mathrm{TiO}_{2}$ paste to fabricate $\mathrm{Au} @ \mathrm{SiO}_{2} \mathrm{NPs}$ incorporated mesoporous $\mathrm{TiO}_{2}$ photoanodes. In addition, we used polyethylene glycol (PEG) based electrolyte to achieve stability of the Au core, inhibiting interaction between the Au core of $\mathrm{Au} @ \mathrm{SiO}_{2} \mathrm{NPs}$ and $\mathrm{I}^{-} / \mathrm{I}_{3}{ }^{-}$ions in the electrolyte. However, the properties of the core-shell nanoparticle-incorporated photoanodes were affected by both the metal cores and shell. Thus, the effects of the shell material on the cell performance must be considered. Until recently, even though a number of researches have been presented to improve the cell performance by utilizing the LSPR effects with metal/ $/ \mathrm{TiO}_{2}$ or $\mathrm{SiO}_{2}$ core-shell structures, the quantitative analyses of the LSPR by metal cores and other changes in the photoanodes by shells are still difficult to separately evaluate. ${ }^{24-26}$ This problem may be solved by comparing the results of the same photoanode structures with and without core metal: core-shell and hollow shell. The hollow shell structure can be prepared by dissolving the core metal of the core-shell sphere by the dissolution reaction with $\mathrm{I}^{-} / \mathrm{I}_{3}{ }^{-}$, which readily diffuses through a shell layer, such as $\mathrm{SiO}_{2} \cdot{ }^{29}$ In this context, $\mathrm{SiO}_{2}$ hollow spheres-incorporated $\mathrm{TiO}_{2}$ photoanode was fabricated to quantify the effects of the LSPR clearly by the Au nanoparticles without disturbing the shell properties or structure. The $\mathrm{TiO}_{2}$ photoanodes incorporating $\mathrm{SiO}_{2}$ hollow spheres have the same morphology as the initial $\mathrm{TiO}_{2}$ photoanodes incorporating $\mathrm{Au} @ \mathrm{SiO}_{2} \mathrm{NPs}$, which is helpful for accurate comparison of photoanodes with and without LSPR. Through this novel approach, the LSPR effect in DSCs can be independently demonstrated with the effect of $\mathrm{SiO}_{2}$ shells, such as the charge injection problem from dyes into the $\mathrm{SiO}_{2}$ shell and the change of morphology and resistance.

\section{Experimental}

\section{Materials}

All chemicals were used without further purification, and water was doubly ionized. The chemicals used for the synthesis of $\mathrm{Au} @ \mathrm{SiO}_{2} \quad \mathrm{NPs}$, hydrogen tetrachloroaurate(III) trihydrate $\left(\mathrm{HAuCl}_{4} \cdot 3 \mathrm{H}_{2} \mathrm{O}\right)$, hexadecyltrimethylammonium bromide
$\left(\mathrm{CH}_{3}\left(\mathrm{CH}_{2}\right)_{15} \mathrm{~N}(\mathrm{Br})\left(\mathrm{CH}_{3}\right)_{3}\right)$, sodium citrate (HOC(COONa)$\left.\left(\mathrm{CH}_{2} \mathrm{COONa}\right)_{2} \cdot 2 \mathrm{H}_{2} \mathrm{O}\right)$, ascorbic acid $\left(\mathrm{C}_{6} \mathrm{H}_{8} \mathrm{O}_{6}\right)$, (3-mercaptopropyl)trimethoxysilane $\left(\mathrm{HS}\left(\mathrm{CH}_{2}\right)_{3} \mathrm{Si}\left(\mathrm{OCH}_{3}\right)_{3}\right)$ and a sodium silicate solution $\left(\mathrm{Na}_{2} \mathrm{O}\left(\mathrm{SiO}_{2}\right) x \cdot x \mathrm{H}_{2} \mathrm{O}\right)$ were purchased from Sigma-Aldrich. For the fabrication of the dye-sensitized solar cells, polyethyleneglycol dimethylether (PEGDME, $M_{\mathrm{w}}: 500$ ), 1methyl-3-propylimidazoliumiodide (MPII), iodine $\left(\mathrm{I}_{2}\right)$ and fumed silica $(\sim 14 \mathrm{~nm})$ were obtained from Sigma-Aldrich. $\mathrm{TiO}_{2}$ paste (DSL 18NR-T) and sensitizer dye, cis-dithiocyanatobis(2,2'-bipyridyl-4,4'-dicarboxylato)ruthenium(II) bis(tetrabutylammonium) (N719), were purchased from Dyesol.

\section{Synthesis of gold nanoparticles}

Au NPs were prepared using a seed-mediated method. ${ }^{30}$ First, 15 $\mathrm{nm}$-diameter $\mathrm{Au} \mathrm{NP}$ seeds were synthesized via citrate reduction. In a typical procedure, $10 \mathrm{ml}$ of a $1 \mathrm{mM}$ gold(III) chloride trihydrate aqueous solution was refluxed at boiling temperature under vigorous stirring, followed by the quick injection of $1 \mathrm{ml}$ of a $39 \mathrm{mM}$ sodium citrate solution. After $15 \mathrm{~min}$, the heating was stopped, and the reaction contents were cool to room temperature. To make larger nanoparticles, a $2 \mathrm{ml}$ seed particle solution was added to $100 \mathrm{ml}$ of a $0.5 \mathrm{mM}$ gold(III) chloride trihydrate aqueous solution containing $0.03 \mathrm{M} \mathrm{CTAB}$ and $1 \mathrm{mM}$ ascorbic acid. The solution was reacted for 4 hours, and the product was collected using centrifugation $(9000 \mathrm{rpm}$, at room temperature for $10 \mathrm{~min}$ ).

\section{Synthesis of gold/silica core-shell nanoparticles}

$\mathrm{Au} @ \mathrm{SiO}_{2}$ NPs were synthesized by a modified procedure previously reported by Obare et al. ${ }^{29}$ In this method, growth of silica was performed after surfactant substitution with a silane coupling group, (3-mercaptopropyl)trimethoxysilane (MPTMS). MPTMS in ethanol was added to the Au NPs solution. After three hours, an aqueous sodium silicate solution was added and reacted for three additional days. The contents were purified several times by precipitation using centrifugation and were redispersed in ethanol.

\section{Paste preparation}

As-prepared Au@SiO ${ }_{2} \mathrm{NPs}$ dispersed in ethanol were added and well mixed with the commercial titanium dioxide $\left(\mathrm{TiO}_{2}\right)$ paste with an average size of $20 \mathrm{~nm}$ (DSL 18NR-T, Dyesol). In order to achieve the same thickness of photoanodes after sintering, excess ethanol from the paste was evaporated using nitrogen to produce a homogenous concentration of paste materials.

\section{Device fabrication}

For the formation of an electron blocking layer between the FTO substrate and oxidized species in the electrolyte, $0.1 \mathrm{M}$ of Ti(Iv) bis(ethyl acetoacetato)diisopropoxide in a 1-butanol solution was spin-coated on FTO glass (TEC 8, Pilkington) followed by sintering at $500{ }^{\circ} \mathrm{C}$. $\mathrm{TiO}_{2}$ photoanodes were fabricated on the blocking layer with $\mathrm{TiO}_{2}$ paste using a doctor blade method followed by sintering at $500{ }^{\circ} \mathrm{C}$ for $15 \mathrm{~min}$. Subsequently, $\mathrm{TiO}_{2}$ nanostructure-coated FTO substrates were dipped into $40 \mathrm{mM}$ 
$\mathrm{TiCl}_{4}$ in $\mathrm{H}_{2} \mathrm{O}$ solution at $70{ }^{\circ} \mathrm{C}$ for $30 \mathrm{~min}$ and sintered at $500{ }^{\circ} \mathrm{C}$ for $15 \mathrm{~min}$.

$\mathrm{TiO}_{2}$ photoanodes were dipped into the $0.3 \mathrm{mM}$ N719 dye (cis-bis(isothiocyanato)bis(2,2'-bipyridyl-4,4'-dicarboxylato) ruthenium(II) bis-tetrabutylammonium, Dyesol) in an acetonitrile and tert-butanol solution $(1: 1 \mathrm{v} / \mathrm{v})$ at $30{ }^{\circ} \mathrm{C}$ for 18 hours and then rinsed with acetonitrile and dried using a stream of nitrogen. A Pt counter electrode was prepared by thermal decomposition of $0.01 \mathrm{M} \mathrm{H}_{2} \mathrm{PtCl}_{6}$ in an isopropyl alcohol solution on the FTO substrate followed by sintering at $500{ }^{\circ} \mathrm{C}$ for 30 min. After loading the dyes onto the $\mathrm{TiO}_{2}$ electrodes, Surlyn (25 $\mu \mathrm{m}$, Solaronix) was attached to the $\mathrm{TiO}_{2}$ photoanode as a spacer. The polymer electrolyte was spread on the spacer gap, and the Pt counter electrode was placed on top.

The electrolyte consists of poly(ethylene glycol dimethyl ether) (PEGDME) ( $M_{\mathrm{w}}: 500$, Sigma-Aldrich), 1-methyl-3-propylimidazolium iodide (MPII, Sigma-Aldrich), iodine ( $\mathrm{I}_{2}$, SigmaAldrich), and fumed silica nanoparticles (14 nm, Sigma-

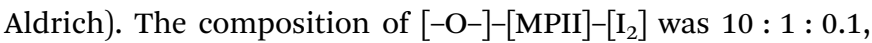
and the silica NPs were $9 \mathrm{wt} \%$ of the total polymer electrolyte. ${ }^{31}$

\section{Solar cell characterization}

The thickness of $\mathrm{TiO}_{2}$ films was characterized with a surface profiler (alpha-step IQ, Tencor) and field emission scanning electron spectroscopy (JSM-6701F, JEOL). Absorption properties of photoanodes were measured by UV-Vis spectroscopy (V-670 UV-Vis spectrophotometer, Jasco) with an integrating sphere. Current-voltage characterization of the DSCs was performed with a Keithley 2400 digital source meter and solar simulator equipped with a $300 \mathrm{~W}$ Xenon arc-lamp (Newport) under a 1 sun illumination ( $\mathrm{AM} 1.5,100 \mathrm{~mW} \mathrm{~cm}^{-2}$ ). The light intensity was calibrated by a silicon solar cell (PV measurement). In addition, the quantum efficiency of DSCs was analyzed by an incident photon to current efficiency (IPCE) (PV measurements, Inc.) as a function of wavelength. The charge transfer resistance and electron lifetime in the photoanodes were characterized by electrochemical impedance spectroscopy (EIS) using an IM6 (Zahner) under dark conditions with a bias potential of $-0.54 \mathrm{~V}$. The frequency was in the range of $1 \mathrm{MHz}$ to $0.1 \mathrm{~Hz}$, and the amplitude was fixed to $10 \mathrm{mV}$. The obtained spectra were fitted and analyzed using Z-View software with equivalent circuits.

The electron diffusion coefficient and electron lifetime of the photoanodes were evaluated by intensity-modulated photocurrent spectroscopy (IMPS) under short-circuit conditions and intensity-modulated photovoltage spectroscopy (IMVS) under open-circuit conditions as a function of light intensity using a controlled intensity modulated photo spectroscopy (CIMPS) system (Zahner) and a white light source (Zahner). The detailed measurement conditions are described elsewhere. ${ }^{32}$

\section{Results and discussion}

Fig. 1a-c show TEM images of three, differently sized Au NPs shelled with thin $\mathrm{SiO}_{2}\left(\mathrm{Au} @ \mathrm{SiO}_{2} \mathrm{NPs}\right)$. The average diameter of $\mathrm{Au}$ NPs obtained by varying the concentration of the $\mathrm{Au}$ precursor was (a) 30, (b) 50, and (c) $160 \mathrm{~nm}$. Subsequently, their surfaces were modified with 3-mercaptopropyl trimethoxysilane (MPTMS), and the thickness of the $\mathrm{SiO}_{2}$ shells were controlled to approximately $11 \mathrm{~nm}$ by adding an aqueous sodium silicate solution.

Even though the Au NPs were protected by the $\mathrm{SiO}_{2}$ shell, the Au cores were dissolved by contact with $\mathrm{I}^{-} / \mathrm{I}_{3}{ }^{-}$ions penetrating the thin silica shell in a few hours. Therefore, the $\mathrm{SiO}_{2}$ shell was treated with $\mathrm{TiCl}_{4}$ to block the penetration of $\mathrm{I}^{-} / \mathrm{I}_{3}{ }^{-}$ions and consequently improve the stability of the Au core nanoparticles against dissolution. In addition, a poly(ethylene glycol) dimethylether (PEGDME, $M_{\mathrm{w}}$ : 500)-based polymer electrolyte, instead of typical acetonitrile-based liquid electrolytes, was used for quasi-solid-state DSCs in order to retard the possible penetration of the $\mathrm{I}^{-} / \mathrm{I}_{3}{ }^{-}$ions through the $\mathrm{SiO}_{2}$ shell. Based on our experimental results, a $\mathrm{SiO}_{2}$ shell thinner than $8 \mathrm{~nm}$ hardly protected the Au core from the electrolyte contact, even though high $M_{\mathrm{w}}$ PEGDME was applied as a viscous solvent for quasisolid electrolytes. Experimental data suggests that $10 \mathrm{~nm}$ was the minimum thickness of the $\mathrm{SiO}_{2}$ shell necessary to protect the Au core from the dissolution.

The localized surface plasmon resonance (LSPR) effects of $\mathrm{Au} @ \mathrm{SiO}_{2}$ NPs by varying the Au core size were characterized using UV-vis spectroscopy, as shown in Fig. 1d. The absorption peak appears at 537, 547, and $565 \mathrm{~nm}$ for $\mathrm{Au} @ \mathrm{SiO}_{2} \mathrm{NPs}$ with the size of the $\mathrm{Au}$ core $/ \mathrm{SiO}_{2}$ shell 30/12, 50/11, and 160/10 nm, respectively. This shift in the absorption band is attributed to the change in the oscillation frequency of LSPR caused by varying the average diameter of the Au NPs. The absorption band of LSPR shifts to a longer wavelength by increasing the size of Au NPs as a result of the decrease in the oscillation frequency. The coupling between the LSPR of the Au NPs and the absorption of dyes is one of the key factors for the enhanced performance of DSCs using Au NPs. In this case, the absorption peak difference or coupling wavelength mismatch of Au NPs $(160 \mathrm{~nm})$ with respect to the N719 dyes was $\sim 40 \mathrm{~nm}$, as shown
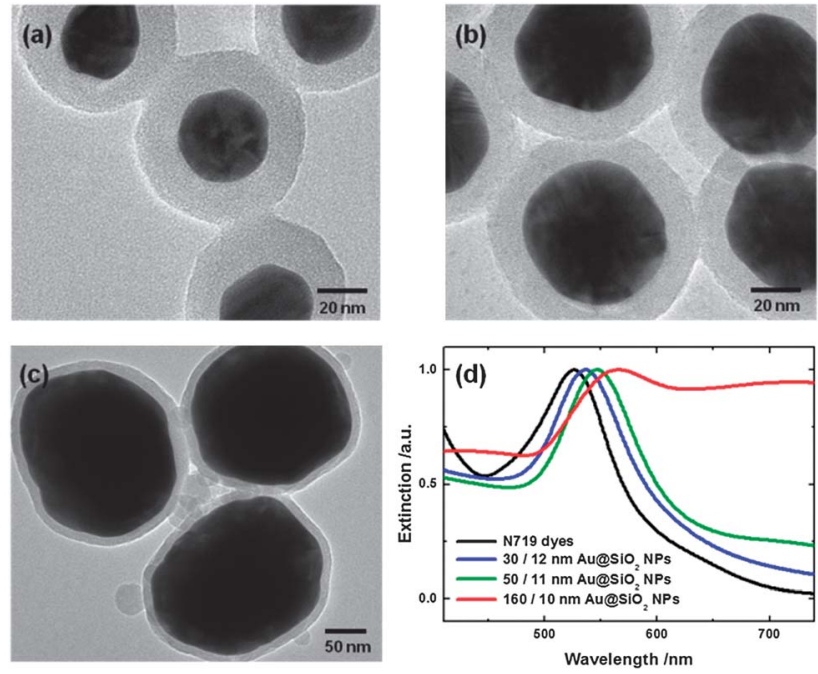

Fig. 1 Transmission electron spectroscopy (TEM) of various sizes of $\mathrm{Au} @ \mathrm{SiO}_{2}$ NPs; (a) 30/12 nm, (b) 50/11 nm, and (c) 160/10 nm. (d) Normalized UV-vis spectrum of the N719 dyes and the Au@ $\mathrm{SiO}_{2}$ NPs in ethanol. 

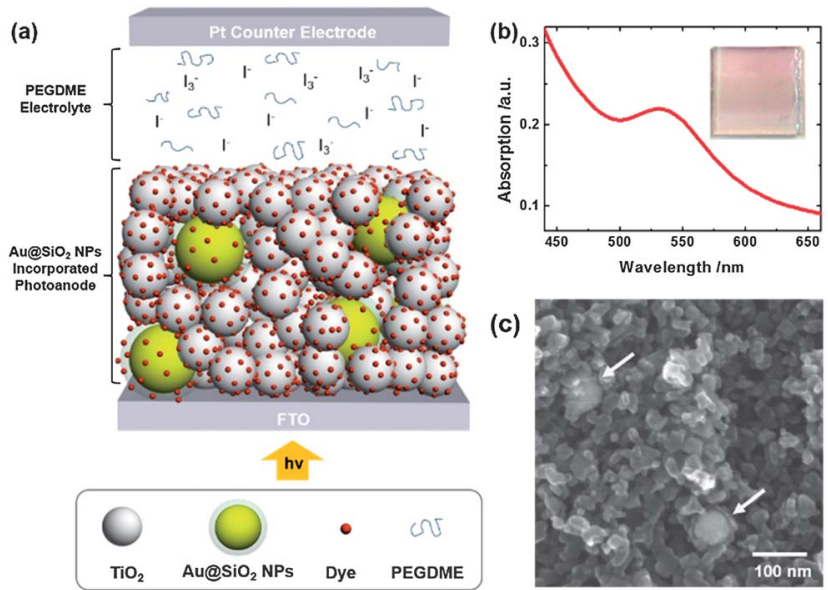

(c)

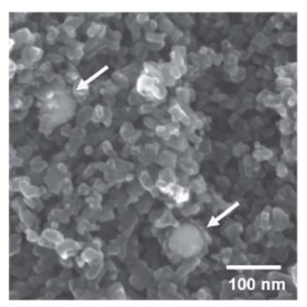

Fig. 2 (a) Schematic illustration of $\mathrm{Au} @ \mathrm{SiO}_{2} \mathrm{NP}$-incorporated photoanode in PEGDME-based quasi-solid-state DSC. (b) UV-vis spectrum, photograph and (c) cross-sectional scanning electron microscopy (SEM) image of $\mathrm{Au@SiO} 2$ NPincorporated photoanode with $\sim 20 \mathrm{~nm}$ diameter $\mathrm{TiO}_{2}$ nanoparticles (white arrows indicate $\mathrm{Au} @ \mathrm{SiO}_{2} \mathrm{NPs}$ ).
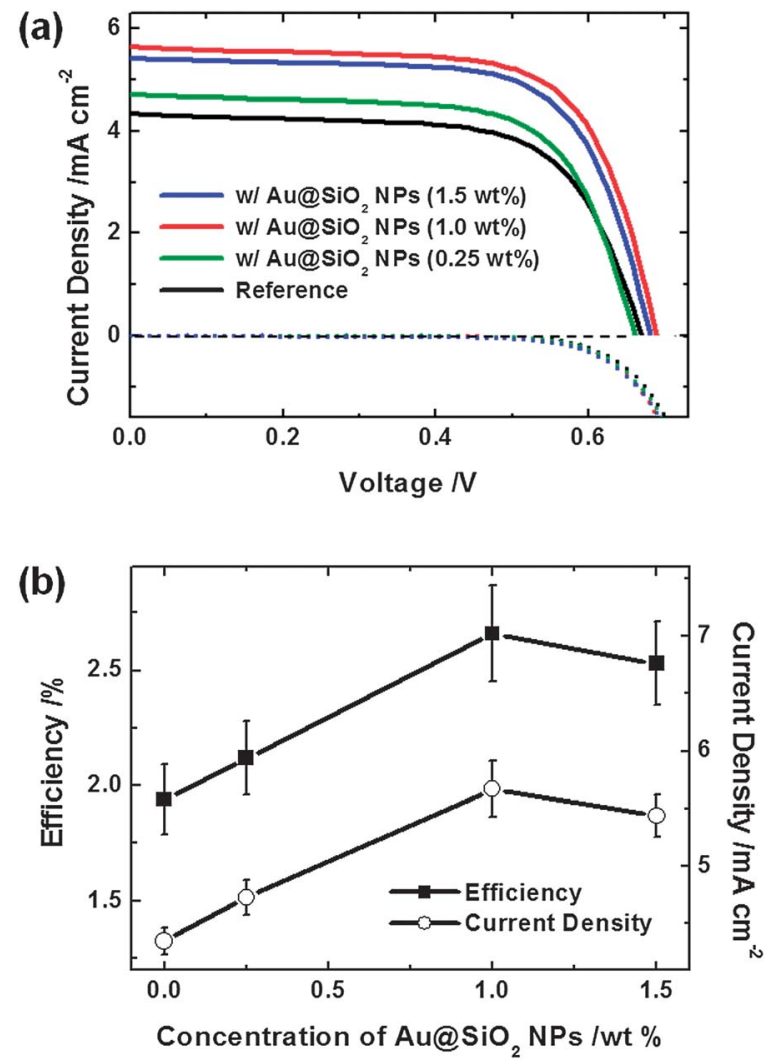

Fig. 3 (a) Photocurrent-voltage characteristics of DSCs with different concentrations of $\mathrm{Au} @ \mathrm{SiO}_{2}$ NPs under illumination (continuous lines) and dark (dotted lines). (b) Power conversion efficiency (closed squares) and short circuit current density (open circles) versus the concentration of $\mathrm{Au} @ \mathrm{SiO}_{2}$ NPs. The error bars indicate the variation of the values for 7 independent measurements for each cell.

in Fig. 1(d). Additionally, when larger Au NPs were incorporated into the $\mathrm{TiO}_{2}$ photoanodes, Mie scattering which is a long range effect should occur and it can be mixed with the effect of LSPR.
Alternatively, as the size of the Au NPs increases, the field enhancement is more widely developed, leading to increased light harvesting of the dyes. Therefore, 50/11 nm Au@ $\mathrm{SiO}_{2} \mathrm{NPs}$ were chosen for the fabrication of photoanodes to investigate the effects of LSPR in DSCs considering their coupling wavelength mismatch, the change in surface area, and the near-field enhancement effects.

Fig. 2a shows the schematic illustration of a $\mathrm{Au@SiO}$ NP-incorporated $\mathrm{TiO}_{2}$ photoanode. The LSPR of Au@SiO $\mathrm{NPs}_{2}$ in $\mathrm{TiO}_{2}$ photoanodes was observed by the reddish photoanode (inset photograph) and by the UV-vis spectrum, as shown in Fig. 2b. Fig. 2c shows Au@SiO ${ }_{2} \mathrm{NPs}$ in the photoanodes surrounded by $\mathrm{TiO}_{2}$ NPs using scanning electron microscopy (SEM). Noticeably, the shapes of the $\mathrm{Au@SiO} \mathrm{NPs}_{2}$ were unchanged after sintering at $500{ }^{\circ} \mathrm{C}$.

The photocurrent-voltage characteristics of DSCs with $\mathrm{TiO}_{2}$ photoanodes incorporating $\mathrm{Au} @ \mathrm{SiO}_{2} \mathrm{NPs}$ are represented in Fig. 3. The film thickness of photoanodes with and without $\mathrm{Au} @ \mathrm{SiO}_{2} \mathrm{NPs}$ was adjusted to $2 \mu \mathrm{m}$ to more clearly characterize the effects of LSPR, which is thinner than a conventional $\mathrm{TiO}_{2}$ layer (Fig. S1 $\dagger$ ). In order to optimize the incorporation of $\mathrm{Au} @ \mathrm{SiO}_{2} \quad \mathrm{NPs}$ for DSC performance, the concentration of $\mathrm{Au} @ \mathrm{SiO}_{2}$ NPs in the $\mathrm{TiO}_{2}$ paste was varied from 0.25 to $1.5 \mathrm{wt} \%$. The short circuit current density $\left(J_{\mathrm{sc}}\right)$ was increased upon the incorporation of $\mathrm{Au} @ \mathrm{SiO}_{2} \mathrm{NPs}$, while the open-circuit voltage $\left(V_{\mathrm{oc}}\right)$ and fill factor (FF) remained nearly unchanged. The $J_{\mathrm{sc}}$ and power conversion efficiency (PCE) of DSCs with the addition of $1.0 \mathrm{wt} \%$ of $\mathrm{Au} @ \mathrm{SiO}_{2} \mathrm{NPs}$ into the $\mathrm{TiO}_{2}$ layer were increased to $5.67 \mathrm{~mA} \mathrm{~cm}^{-2}$ and $2.66 \%$, respectively, with respect to the same thickness reference $\mathrm{TiO}_{2}$ photoanode without $\mathrm{Au} @ \mathrm{SiO}_{2} \mathrm{NPs}$ $\left(4.35 \mathrm{~mA} \mathrm{~cm}^{-2}, 1.94 \%\right)$. However, at concentrations greater than $1.0 \mathrm{wt} \% \mathrm{Au} @ \mathrm{SiO}_{2} \mathrm{NPs}$, the $J_{\mathrm{sc}}\left(5.44 \mathrm{~mA} \mathrm{~cm}^{-2}\right)$ and PCE $(2.53 \%)$ were slightly decreased, as shown in Fig. $3 \mathrm{~b}$ and Table 1 . The inclusion of Au@SiO $\mathrm{NPs}_{2}$ in the photoanode may have possible side effects. First, the $\mathrm{Au} @ \mathrm{SiO}_{2}$ NPs could inhibit the light absorption of dyes in the photoanodes while the $\mathrm{Au} @ \mathrm{SiO}_{2} \mathrm{NPs}$ in the photoanodes absorb the incident light as well as dyes but without converting photons to charges. ${ }^{26}$ On that account, the light harvesting efficiency may slightly decrease when the concentration of $\mathrm{Au} @ \mathrm{SiO}_{2} \mathrm{NPs}$ in the photoanode becomes higher than the critical point. Secondly, Au@SiO ${ }_{2} \mathrm{NPs}$ with a size of $\sim 70 \mathrm{~nm}$ decrease the total amount of dye loading in the photoanodes due to the smaller surface area relative to $20 \mathrm{~nm}$ $\mathrm{TiO}_{2}$ NPs. Finally, it is difficult to inject electrons from the excited dyes into the insulator $\mathrm{SiO}_{2}$ shell. These side effects of the inclusion of $\mathrm{Au} @ \mathrm{SiO}_{2}$ NPs may result in a decrease in photocurrent and consequently the photovoltaic performance of DSCs to a small extent. However, the overall energy conversion efficiency increased from 1.94 to $2.66 \%$, which was a nearly $30 \%$ improvement, suggesting that the positive effects of LSPR are significant. Therefore, the performance was further characterized in the following sections. In order to evaluate the quantitative effects of LSPR from Au cores excluding the $\mathrm{SiO}_{2}$ shell effects, the $\mathrm{Au} @ \mathrm{SiO}_{2}$ NP-incorporated photoanodes with and without the $\mathrm{Au}$ cores were compared. Experimentally, $\mathrm{TiO}_{2}$ photoanodes incorporating $\mathrm{SiO}_{2}$ hollow spheres with the same size of $\mathrm{Au} @ \mathrm{SiO}_{2} \mathrm{NP}$ shell but without the $\mathrm{Au}$ core were 
Table $1 \quad I-V$ characteristics of the DSCs with $\mathrm{TiO}_{2}$ photoanodes employing $\mathrm{Au} @ \mathrm{SiO}_{2} \mathrm{NPs}_{\text {and }} \mathrm{SiO}_{2}$ hollow spheres ${ }^{a}$

\begin{tabular}{|c|c|c|c|c|c|}
\hline Type of $\mathrm{TiO}_{2}$ photoanode & $\begin{array}{l}\text { Concentration } \\
\text { of } \mathrm{Au} @ \mathrm{SiO}_{2} \mathrm{NPs}(\mathrm{wt} \%)\end{array}$ & $V_{\mathrm{oc}}(\mathrm{V})$ & $\begin{array}{l}J_{\mathrm{sc}} \\
\left(\mathrm{mA} \mathrm{cm}^{-2}\right)\end{array}$ & $\mathrm{FF}(\%)$ & $\begin{array}{l}\text { Efficiency } \\
(\%)\end{array}$ \\
\hline Reference (only $\mathrm{TiO}_{2}$ ) & - & 0.664 & 4.35 & 67.0 & 1.94 \\
\hline & 1.0 & 0.684 & 5.67 & 68.6 & 2.66 \\
\hline & 1.5 & 0.676 & 5.44 & 68.7 & 2.53 \\
\hline $\mathrm{w} / \mathrm{SiO}_{2}$ hollow spheres & 1.0 & 0.665 & 4.4 & 67.7 & 1.97 \\
\hline
\end{tabular}

${ }^{a}$ The thickness of $\mathrm{TiO}_{2}$ photoanodes are adjusted with $2 \mu \mathrm{m}$; measured under 1 sun condition (AM 1.5, $100 \mathrm{~mW} \mathrm{~cm}^{-2}$ ) with $0.25 \mathrm{~cm}^{2}$ active area.

(a)

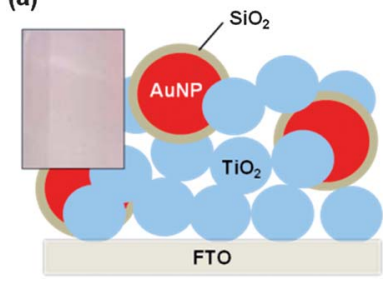

(b)

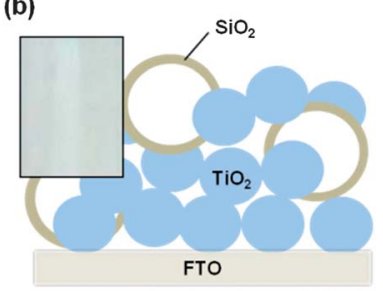

Fig. 4 Schemes of the $\mathrm{TiO}_{2}$ photoanodes incorporating (a) $\mathrm{Au} @ \mathrm{SiO}_{2} \mathrm{NPs}$ and (b) $\mathrm{SiO}_{2}$ hollow spheres. Photographs of the corresponding photoanodes are shown in the insets.

introduced by dipping $\mathrm{Au} @ \mathrm{SiO}_{2} \mathrm{NP}^{-i n c o r p o r a t e d ~ p h o t o a n o d e s ~}$ in an $\mathrm{I}^{-} / \mathrm{I}_{3}{ }^{-}$liquid electrolyte for a few hours, which has the same morphology and thickness of the photoanode with $\mathrm{Au} @ \mathrm{SiO}_{2}$ NPs. As expected, the $\mathrm{SiO}_{2}$ hollow sphere was formed without a change in morphology due to the exclusive dissolution reaction eqn (1) of $\mathrm{Au}$ with $\mathrm{I}^{-} / \mathrm{I}_{3}{ }^{-}$ions, which was easily demonstrated by the disappearance of the reddish color and characterized by scanning electron microscopy, as shown by the inset photographs of Fig. 4 and S2(a). $\dagger$ Fig. 5a shows the decreased light absorption of N719 dyes upon incorporating the $\mathrm{SiO}_{2}$ hollow spheres rather than $\mathrm{Au@SiO} \mathrm{NPs}_{2}$, indicating the effects of the presence of $\mathrm{Au}$ cores. The amount of dyes adsorbed on the $\mathrm{TiO}_{2}$ surface were characterized and this result shows that the dyes loaded in $\mathrm{SiO}_{2}$ hollow sphere incorporated photoanodes are nearly the same as the amount in the $\mathrm{Au} @ \mathrm{SiO}_{2}$ NPs incorporated photoanode (Fig. S2(c) $\dagger$ ). The only difference between these photoanodes was the Au cores, suggesting that

the enhanced light absorption is primarily attributed to the LSPR effects of the Au core. In order to confirm the LSPR effect more distinctly, we characterized absorption spectrum of the photoanodes additionally with N749 dyes (green dye) which absorb longer wavelength of light (>600 nm) compare to Au NPs $(\sim 530 \mathrm{~nm})$, as shown in Fig. 5a. Through the distinguished peaks of LSPR and light absorption of N749 dyes, the effect of LSPR on the enhanced light absorption of dyes was clearly verified. Moreover, almost the same reflectance of $\mathrm{Au} @ \mathrm{SiO}_{2} \mathrm{NPs}$ and $\mathrm{SiO}_{2}$ hollow spheres incorporated photoanodes were characterized by UV-vis spectroscopy with an integrating sphere and both photoanodes show only $\sim 2 \%$ off-specular reflection by scattered light (Fig. S3†). This provides convincing evidence that absorption enhancement was mainly induced by LSPR which is near-field effect and not Mie scattering which is far-field effect.

Fig. 5b shows the photocurrent-voltage $(J-V)$ characteristics of DSCs that are consistent with the results obtained from the difference in the light absorption, as shown in Fig. 5a. DSCs based on the $\mathrm{TiO}_{2}$ photoanode incorporating $\mathrm{Au} @ \mathrm{SiO}_{2}$ NPs exhibited $\sim 28 \%$ greater $J_{\mathrm{sc}}$ and PCE than those with the hollow $\mathrm{SiO}_{2}$ spheres. The increase of $J_{\text {sc }}$ agrees well with the incident photon-to-current efficiency (IPCE) results, and the difference obtained by subtracting IPCE values increased at the same wavelength as the absorption band of LSPR (Fig. 5c). Moreover, the photoanode incorporating $\mathrm{SiO}_{2}$ hollow spheres shows similar $J_{\mathrm{sc}}$ of $4.4 \mathrm{~mA} \mathrm{~cm}^{-2}$ and PCE of $1.97 \%$ with respect to the reference $\mathrm{TiO}_{2}$ photoanode, as summarized in Table 1. For the photoanodes incorporating $\mathrm{SiO}_{2}$ hollow spheres, only the $\mathrm{Au}$ cores were removed from the $\mathrm{Au} @ \mathrm{SiO}_{2}$ NPs photoanode, while
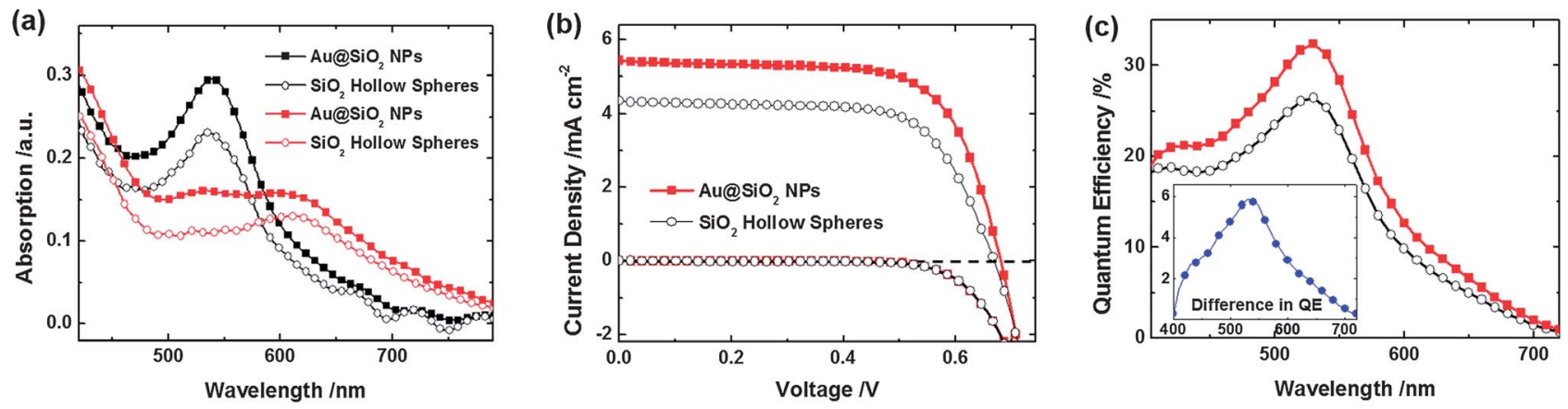

Fig. 5 (a) UV-vis spectrum of $\mathrm{TiO}_{2}$ photoanodes with N719 dyes (black lines) and N749 dyes (red lines). (b) Photocurrent-voltage characteristics and (c) IPCE spectrum of DSCs characterized with the inclusion of $\mathrm{Au} @ \mathrm{SiO}_{2} \mathrm{NPs}$ (the red closed squares) and $\mathrm{SiO}_{2}$ hollow spheres (the black open circles). Devices had $2 \mu \mathrm{m}$ of the TiO 2 films and photovoltaic performance was measured under 1 sun condition (AM 1.5, $100 \mathrm{~mW} \mathrm{~cm}$ solar illumination) with $0.25 \mathrm{~cm}^{2}$ active area. 
(a)
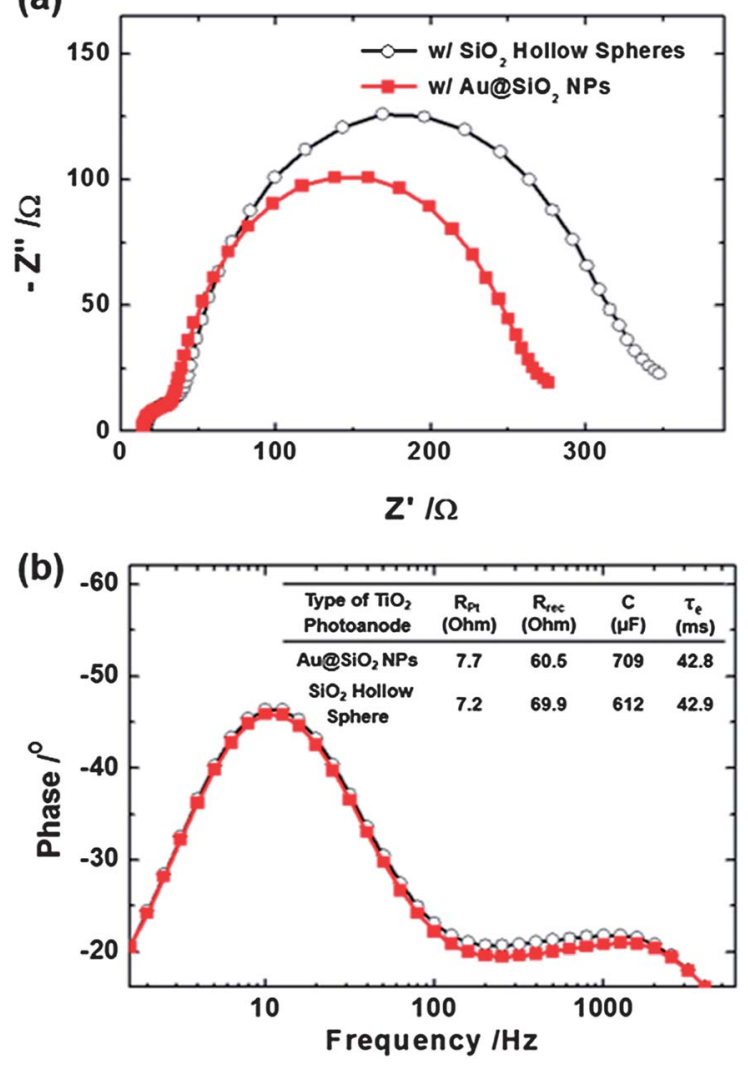

Fig. 6 Impedance spectra of DSCs with photoanodes incorporating $\mathrm{Au} @ \mathrm{SiO}_{2}$ $\mathrm{NPs}$ (closed squares) and $\mathrm{SiO}_{2}$ hollow spheres (open circles) in the dark condition with a bias potential of $-0.54 \mathrm{~V}$ ((a) Nyquist plot and (b) Bode plot). Charge transfer resistance $\left(R_{\mathrm{Pt}}\right)$, recombination resistance $\left(R_{\text {rec }}\right)$, capacitance $(C)$ and electron lifetime $\left(\tau_{\mathrm{e}}\right)$ of photoanodes are shown in the inset table.

the surface area and morphology of the $\mathrm{TiO}_{2}$ photoanode were unchanged. Thus, the small change of the photovoltaic performance between the reference and $\mathrm{SiO}_{2}$ hollow sphere photoanodes suggested that the effects of the changes in surface area and morphology upon incorporating $\mathrm{Au} @ \mathrm{SiO}_{2} \mathrm{NPs}_{\mathrm{N}}$ on the cell performance were nearly negligible. The performance enhancement upon incorporating $\mathrm{Au} @ \mathrm{SiO}_{2} \mathrm{NPs}$ into a photoanode is mostly due to the LSPR effects of the Au nanoparticles.

Electrochemical impedance spectroscopy (EIS) was performed in dark conditions with a bias potential of $-0.54 \mathrm{~V}$ (Fig. 6) to characterize the cell performance, and the performance parameters were obtained by fitting with the general transmission model of DSCs. ${ }^{33}$ In Fig. 6a, the Nyquist plots show two semicircles. The first semicircle at high frequency was attributed to the charge transfer resistance at the Pt counter electrode-polymer electrolyte interface $\left(R_{\mathrm{Pt}}\right)$, and the second semicircle at mid-frequency was associated with the electron recombination resistance $\left(R_{\text {rec }}\right)$ and capacitance $(C)$ at the $\mathrm{TiO}_{2}-$ polymer electrolyte interface. For Bode plots, the characteristic frequency peak in the mid-frequencies was unchanged (Fig. 6b), indicating nearly the same electron lifetimes for the two samples. The values are listed in the inset table of Fig. 6b.

The roles of the $\mathrm{Au} @ \mathrm{SiO}_{2} \mathrm{NPs}$ in the electron lifetime and the electron diffusion coefficient in the $\mathrm{TiO}_{2}$ photoanodes were also
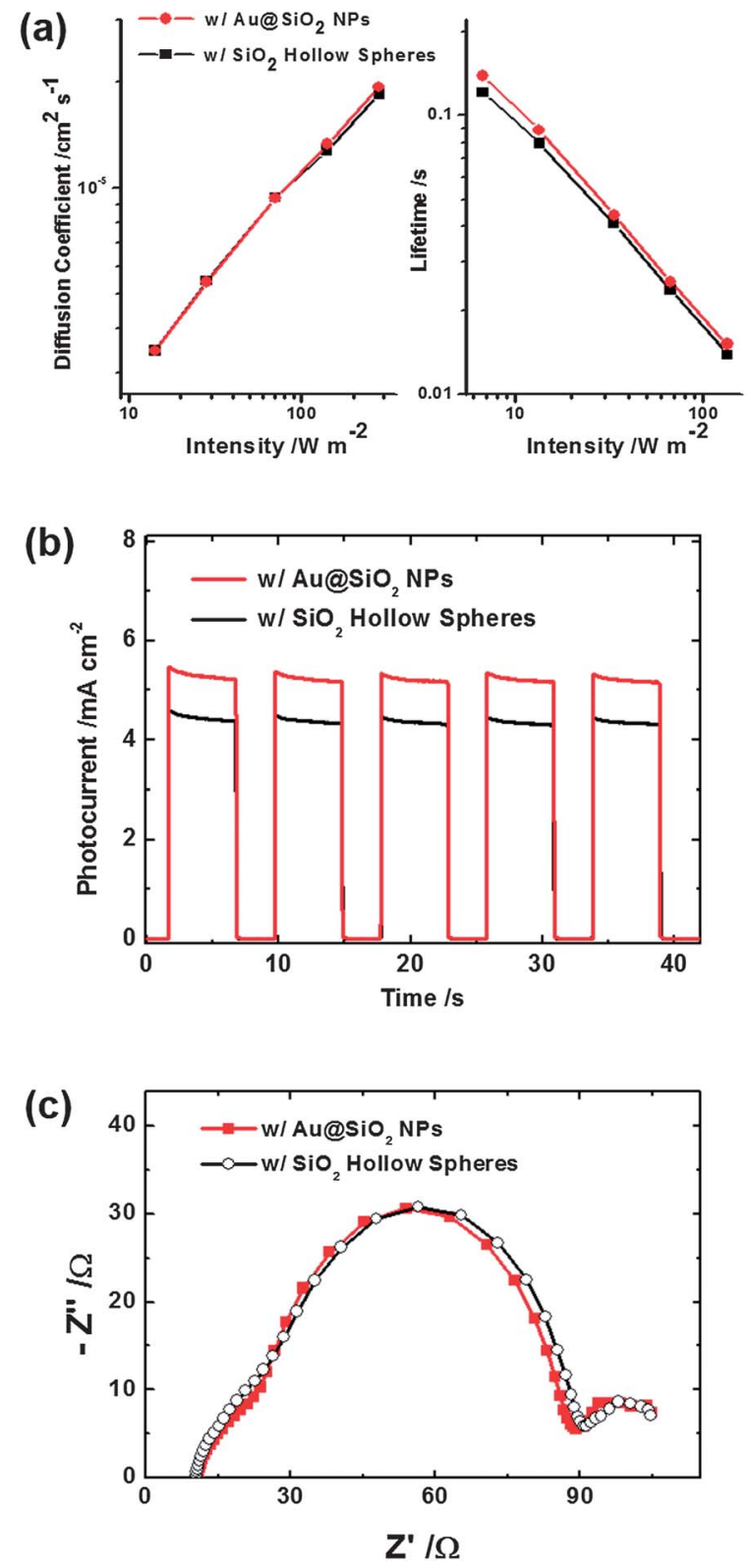

Fig. 7 (a) The electron diffusion coefficient (left) and the electron lifetime (right) determined by incident-modulated photocurrent spectroscopy (IMPS) and incident-modulated photovoltage spectroscopy (IMVS) as a function of light intensity, respectively. (b) Photocurrent transient measurement results and (c) impedance spectra of DSCs with photoanodes incorporating $\mathrm{Au} @ \mathrm{SiO}_{2}$ NPs and $\mathrm{SiO}_{2}$ hollow spheres. Impedance spectrum was characterized under illumination with bias potential of $-0.65 \mathrm{~V}$.

evaluated with incident-modulated photovoltage spectroscopy (IMVS) and incident-modulated photocurrent spectroscopy (IMPS) as a function of the light intensity given in Fig. 7a. In accordance with the EIS measurements, the electron lifetime upon the inclusion of the $\mathrm{Au} @ \mathrm{SiO}_{2}$ NPs was unchanged compared to that of the photoanode with the hollow $\mathrm{SiO}_{2}$ spheres. Furthermore, the electron diffusion coefficient was also unchanged, and thus the diffusion lengths $\left(L_{\mathrm{n}}, L_{\mathrm{n}}=\right.$ $\left.\left(D_{\mathrm{n}} \tau_{\mathrm{n}}\right)^{1 / 2}\right)$ derived from these values were almost same between the photoanodes containing $\mathrm{Au} @ \mathrm{SiO}_{2} \mathrm{NPs}$ with and without the 
$\mathrm{Au}$ core nanoparticles. In addition, the transient photocurrent and the diffusion coefficients of electrolyte $\left(D\left[\mathrm{I}_{3}{ }^{-}\right]\right)$were measured, as shown in Fig. $7 \mathrm{~b}$ and c. Nearly the same values of $\mathrm{Au} @ \mathrm{SiO}_{2} \mathrm{NPs}\left(2.36 \times 10^{-7} \mathrm{~cm}^{2} \mathrm{~s}^{-1}\right)$ and hollow $\mathrm{SiO}_{2}$ spheres $\left(2.38 \times 10^{-7} \mathrm{~cm}^{2} \mathrm{~s}^{-1}\right)$ incorporated photoanodes were evaluated. These results reveal that despite the enhanced light absorption of photoanodes by LSPR, the Au NPs had no influence on the electrochemical properties in the photoanodes and electrolyte due to the presence of the insulating layer inhibiting interaction between $\mathrm{Au}$ cores and electrolyte.

\section{Conclusions}

$\mathrm{Au} @ \mathrm{SiO}_{2}$ NPs incorporated into a conventional mesoporous $\mathrm{TiO}_{2}$ photoanode resulted in a significant increase in the energy conversion efficiency (up to $36 \%$ from 1.94 to $2.66 \%$ with a 2 $\mu \mathrm{m}$-thick photoanode under 1 sun illumination condition) in quasi-solid state DSCs, mostly due to the enhanced photocurrent density from 4.35 to $5.67 \mathrm{~mA} \mathrm{~cm}^{-2}$ by the LSPR effects of the Au NPs. In addition, the LSPR effects were directly observed by comparing results between the $\mathrm{Au} @ \mathrm{SiO}_{2}$ NPs- and $\mathrm{SiO}_{2}$ hollow spheres-incorporated $\mathrm{TiO}_{2}$ photoanodes, where the hollow spheres were obtained by dissolving the Au core with $\mathrm{I}^{-} /$ $\mathrm{I}_{3}{ }^{-}$ions and had same morphologies as $\mathrm{Au} @ \mathrm{SiO}_{2} \mathrm{NPs}$. The influences from LSPR of the Au core in optical, electrochemical, and photovoltaic properties of the photoanodes were characterized by UV-vis spectroscopy and EIS measurements separate from the effect of $\mathrm{SiO}_{2}$ shell and morphology change. From this, we demonstrated that the incorporation of the Au@SiO ${ }_{2} \mathrm{NPs}$ enhanced the light harvesting efficiency of dye molecules without changing the electron lifetime and diffusion coefficient of the $\mathrm{TiO}_{2}$ photoanodes and were very effective in improving the power conversion efficiency of DSCs.

\section{Acknowledgements}

S. Wooh $\ddagger$ and Y. Lee $\$$ contributed equally to this work. This work was financially supported by the National Creative Research Initiative Center for Intelligent Hybrids (No. 20100018290) through the National Research Foundation of Korea (NRF) grant funded by the Korea government (MSIP). This work was also in part supported by the International Research Training Group (IRTG): Self Organized Materials for Optoelectronics, jointly supported by the DFG (Germany) and NRF (Korea). Additionally, this work was supported by the National Research Foundation of Korea (NRF) grant funded by the Korea government (MSIP) for the Center for Next Generation Dyesensitized Solar Cells (No. 2013004800).

\section{Notes and references}

1 B. O'Regan and M. Grätzel, Nature, 1991, 353, 737.

2 M. Grätzel, Nature, 2001, 414, 338.

3 M. K. Nazeeruddin, F. D. Angelis, S. Fantacci, A. Selloni, G. Viscardi, P. Liska, S. Ito, B. Takeru and M. Grätzel, J. Am. Chem. Soc., 2005, 127, 16835.
4 A. Yella, H.-W. Lee, H. N. Tsao, C. Yi, A. K. Chandiran, M. K. Nazeeruddin, W. W.-G. Diau, C.-Y. Yeh, S. M. Zakeeruddin and M. Grätzel, Science, 2011, 334, 629.

5 C.-Y. Chen, M. Wang, J.-Y. Li, N. Pootrakulchote, L. Alibabaei, C.-H. Ngoc-le, J.-D. Decoppet, J.-H. Tsai, C. Grätzel, C.-G. Wu, S. M. Zakeeruddin and M. Grätzel, ACS Nano, 2009, 3, 3103.

6 N. Cai, S.-J. Moon, L. Cevey-Ha, T. Moehl, R. Humphry-Baker, P. Wang, S. M. Zakeeruddin and M. Grätzel, Nano Lett., 2011, 11, 1452.

7 B. E. Hardin, E. T. Hoke, P. B. Armstrong, J. H. Yum, P. Comte, T. Torres, J. M. J. Frechet, M. K. Nazeeruddin, M. Grätzel and M. D. McGehee, Nat. Photonics, 2009, 3, 406.

8 W. Zhao, Y. J. Hou, X. S. Wang, B. W. Zhang, Y. Cao, R. Yang, W. B. Wang and X. R. Xiao, Sol. Energy Mater. Sol. Cells, 1999, 58, 173.

9 J.-H. Yum, S.-R. Jang, P. Walter, T. Geiger, F. Nüesch, S. Kim, J. Ko, M. Grätzel and M. K. Nazeeruddin, Chem. Commun., 2007, 4680.

10 K. Lee, S. W. Park, M. J. Ko, K. Kim and N.-G. Park, Nat. Mater., 2009, 8, 665.

11 J.-H. Yum, E. Baranoff, S. Wenger, M. K. Nazeeruddin and M. Grätzel, Energy Environ. Sci., 2011, 4, 842.

12 S.-H. A. Lee, N. M. Abrams, P. G. Hoertz, G. D. Barber, L. I. Halaoui and T. E. Mallouk, J. Phys. Chem. B, 2008, 112, 14415.

13 J.-H. Shin and J. H. Moon, Langmuir, 2011, 27, 6311.

14 S.-H. Han, S. Lee, H. Shin and H. S. Jung, Adv. Energy Mater., 2011, 1, 546.

15 Y. A. Akimov, K. Ostrikov and E. P. Li, Plasmonics, 2009, 4, 107.

16 Y. A. Akimov, W. S. Koh and K. Ostrikov, Opt. Express, 2009, 17, 10195.

17 S.-S. Kim, S.-I. Na, J. Jo, D.-Y. Kim and Y.-C. Nah, Appl. Phys. Lett., 2008, 93, 073307.

18 B. Ding, B. J. Lee, M. Yang, H. S. Jung and J.-K. Lee, Adv. Energy Mater., 2011, 1, 415.

19 J. Qi, X. Dang, P. T. Hammond and A. M. Belcher, ACS Nano, 2011, 5, 7108.

20 S. W. Sheehan, H. Noh, G. W. Brudvig, H. Cao and C. Schmuttenmaer, J. Phys. Chem. C, 2013, 117, 927.

21 H. Choi, W. T. Chen and P. V. Kamat, ACS Nano, 2012, 6, 4418.

22 D. Zhang, M. Wang, A. G. Brolo, J. Shen, X. Li and S. Huang, J. Phys. D: Appl. Phys., 2013, 46, 024005.

23 S.-J. Lin, K.-C. Lee, J.-L. Wu and J.-Y. Wu, Sol. Energy, 2012, 86, 2600.

24 S. D. Standridge, G. C. Schatz and J. T. Hupp, J. Am. Chem. Soc., 2009, 131, 8407.

25 S. D. Standridge, G. C. Schatz and J. T. Hupp, Langmuir, 2009, 25, 2596.

26 M. D. Brown, T. Suteewong, R. S. S. Kumar, V. D'Innocenzo, A. Petrozza, M. M. Lee, U. Wiesner and H. J. Snaith, Nano Lett., 2011, 11, 438.

27 I.-K. Ding, J. Zhu, W. Cai, S.-J. Moon, N. Cai, P. Wang, S. M. Zakeeruddin, M. Grätzel, 
M. L. Brongersma, Y. Cui and M. D. McGehee, Adv. Energy Mater., 2011, 1, 52.

28 Y. Nakao and K. Soneb, Chem. Commun., 1996, 897.

29 S. O. Obare, N. R. Jana and C. J. Murphy, Nano Lett., 2001, 1, 601.

30 J. Rodriguez-Fernandez, J. Perez-Juste, J. G. Abajo and L. M. Liz-Marzan, Langmuir, 2006, 22, 7007.
31 J. H. Kim, M.-S. Kang, Y. J. Kim, J. Won, N.-G. Park and Y. S. Kang, Chem. Commun., 2004, 1662.

32 L. M. Peter and K. G. U. Wijayantha, Electrochim. Acta, 2000, 45, 4543.

33 J. Bisquert, G. Garcia-Belmonte, F. Fabregat-Santiago and A. Compte, Electrochem. Commun., 1999, 1, 429. 